membrane depolarization (i.e. JC-1 flow analysis); no activation of caspase-9). Universal caspases inhibition and neutralization of FasL abrogated the stretch-induced apoptosis.

Conclusion Prolonged mechanical ventilation induces apoptosis of alveolar type II cells in newborn rats and the cellular mechanism involves activation of the extrinsic death pathway via the FasL/Fas system.

\section{EFFECTIVENESS OF FETAL PERFLUROCARBON THERAPY FOR LUNG HYPOPLASIA IN DIAPHRAGMATIC HERNIA}

doi:10.1136/archdischild-2012-302724.0234

'S Herber-Jonat, ${ }^{2} \mathrm{~A}$ Vuckovic, ${ }^{1} \mathrm{R}$ Mittal, ${ }^{3} \mathrm{~J}$ Jani, 'AW Flemmer. 'Div. of Neonatology, University Children's Hospital, LMU Munich, Munich, Germany; 'Laboratory of Physiology and Physiopathology, Faculty of Medicine, Université Libre de Bruxelles; ${ }^{3}$ Department of Obstetrics and Gynecology, CHU Brugmann, Brussel, Belgium

Aims To assess the effects of fetal, intratracheal perfluoroctylbromid (PFOB) instillation on lung-mechanics and gene expression of Surfactant and developmental proteins in a newborn rabbit model of lung hypoplasia.

Methods On day 23/31, diaphragmatic hernia was induced by fetal surgery in two fetuses/doe. On day 28/31, the fetuses were randomly instilled with intratracheal $\mathrm{PFOB}(\mathrm{CDH}-\mathrm{PFOB})$ or saline (CDH-saline). After term delivery, the fetuses were ventilated (30 min) and lung-mechanics were measured. Lung-tobody-weight-ratio (LBWR) and mRNA levels of different proteins were determined. Non-operated littermates served as controls. Gene expression was expressed as fold-induction relative to controls.

Results LBWR showed an increase in CDH-PFOB as compared to $\mathrm{CDH}$-saline ( $\mathrm{p}=0.05)$. Total lung capacity (TLC), static lung compliance (Cst), and RTq-PCR are shown below ( $+p<0.05$ as compared to control, ${ }^{*} \mathrm{p}<0.05$ as compared to $\mathrm{CDH}$-saline):

\section{Abstract 234 Table 1}

\begin{tabular}{llll}
\hline Mean $(\mathbf{9 5} \%-C I)$ & control $(\mathbf{n}=\mathbf{9})$ & CDH-saline $(\mathbf{n}=\mathbf{8})$ & CDH-PF0B $(\mathbf{n}=\mathbf{8})$ \\
\hline TLC $(\mu \mathrm{l} / \mathrm{g})$ & $33.34(30.29 ; 36.38)$ & $15.42(10.25 ; 20.58)+$ & $21.68(18.64 ; 24.72)+{ }^{*}$ \\
Cst $\left(\mathrm{ml} / \mathrm{cmH}{ }_{2} 0^{*} \mathrm{~kg}\right)$ & $2.36(2.12 ; 2.60)$ & $1.20(0.85 ; 1.55)+$ & $2.08(1.47 ; 2.70)+{ }^{*}$ \\
SpA & $1(0.53 ; 1,88)$ & $0.56(0.24 ; 1.39)+$ & $0.47(0.15 ; 1.37)+$ \\
SpB & $1(0.44 ; 2,3)$ & $1.55(0.68 ; 3.29)+$ & $0.76(0.29 ; 1.72)^{*}$ \\
SpC & $1(0.3 ; 3,3)$ & $1.72(0.88 ; 4.66)+$ & $0.92(0.29 ; 2.77)^{*}$ \\
TGF-ß2 & $1(0.12 ; 8,5)$ & $1.43(0.10 ; 10,18)$ & $0.92(0.10 ; 9,03)$ \\
prepro $\alpha-1$ coll 1 & $1(0.44 ; 2,27)$ & $1.64(0.78 ; 4.30)+$ & $1.04(0.38 ; 3,14)$ \\
\hline
\end{tabular}

Conclusions In contrast to previous data addressing tracheal occlusion, PFOB improved TLC and Cst. PFOB also resulted in normalization of Surfactantproteins without inducing extracellularmatrix proteins. Thus, $\mathrm{PFOB}$ instillation appears to be a promising therapy for use in fetal lung hypoplasia.

\section{ROLE OF EARLY PROTEIN INTAKE IN OBESITY DEVELOPMENT}

doi:10.1136/archdischild-2012-302724.0235

MF Rolland-Cachera. UREN, University Paris 13, Bobigny, France

There is now convincing evidence that early life factors exert long-lasting influence on health. Birth weight and growth seem to be highly sensitive to nutritional factors during pregnancy and in early life. The nutrient balance of the diet in the first years of life is likely to have important impact on growth and later health. Mother's milk contains a high proportion of fat (52\%) and low proportion of protein (6\%). After weaning, the infant diet in industrialized countries is in sharp contrast with the composition of human milk. The fat content suddenly drops and the protein content increases, reaching 3 to 4 times the protein needs. The beneficial effect of human milk could be attributable to its nutrient composition. Indeed, several studies have shown that the high protein content of the diet could have detrimental effects on growth. High protein intake is associated with an early adiposity rebound which predicts later health risks. However, the mechanisms and the cause-effect relationships remain to be elucidated. Low energy dense diet can affect leptin and ghrelin concentrations in early life and program later resistance. Besides, excessive protein intake might accelerate growth by increasing insulin-like growth factor. Optimal growth is desirable, as stunting and rapid growth as well are risk factors for various diseases. These observations stress the importance of providing nutritional intakes adapted to nutritional needs at various stages of growth.

\section{INTERMITTENT HYPOXIA: EFFECTS ON BRAIN STEM OF OXIDATIVE STRESS AND NRF2 TRANSCRIPTION FACTOR ACTIVATION IN A RAT PUP MODEL}

doi:10.1136/archdischild-2012-302724.0236

${ }^{1} \mathrm{M}$ Vento, ${ }^{2} \mathrm{~J}$ Escobar, ${ }^{3} \mathrm{~J}$ Kuligowski, ${ }^{4} \mathrm{~K}$ Prabha, ${ }^{4} \mathrm{RJ}$ Martin, 'E Cubells, ${ }^{4} \mathrm{O}$ Koroglu. ${ }^{1}$ Division of Neonatology, University and Polytechnic Hospital La Fe; ${ }^{2}$ Neonatal Research Unit; ${ }^{3}$ Division of Neonatology, Health Reseach Institute La Fe, Valencia, Spain; ${ }^{4}$ Division of Neonatology, Rainbow Babies \& Childrens' Hospital, Cleveland, OH, USA

Background Apnea of prematurity which is a common condition in the neonatal period caused by immature brainstem respiratory neural output may result in intermittent hypoxia and cause of oxidative stress during this vulnerable developmental period.

Objective To test if chronic intermittent hypoxia $(\mathrm{CIH})$ alters oxidative metabolism and resultant redox status in the medulla of rat pups.

Methods Litters of 10 rat pups and their dams were assigned to: normoxia (controls) and intermittent hypoxia ( $\mathrm{Hx})$. Exposure occurred from P1-P7. CIH consisted of exposing rat pups to alternating cycles of $\mathrm{N} 2$ and air: 45 seconds of hypoxia (nadir of $5 \% \mathrm{O}_{2}$ ) was administered every 5 minutes for 8 hours/day. For controls, animals were kept at air. On the eighth day, brainstems were harvested, snap-frozen in liquid nitrogen. Reduced (GSH) and oxidized (GSSG) glutathione, and precursors -glutamylcysteine (-G-cysteine) and L-cysteine in medulla were determined by UPLC-MS/MS and MDA in medulla was determined by HPLC.

Results GSH was significantly reduced in medulla of rat pups submitted to chronic intermittent hypoxic $(\mathrm{CIH})$ episodes associated with reduction in GSH/GSSG ratio. GSH precursors were also significantly lower in the brainstem of the Hx group.

Conclusions Intermittent hypoxic episodes in rat pups cause a significant reduction in GSH and its precursors in the developing brainstem. GSH and precursors are major determinants of redox status. These alterations may activate transcription factors relevant to the expression of antioxidant enzymes and inflammation. We speculate that oxidant stress may impair central respiratory control and contribute to further enhance recurrent apnea/impaired oxygenation. 